Os autores examinam a história das escolas especiais até nossos dias. Trinta anos atrás, cssas escolas tinham uma orientação empirista e repetitiva, o que era um incentivo às perseveraçoes $e$ is estereotipias. A partir daí, inciaram-se esforços em direçio d̀ escola inclusiva e em direçĩo a transformaçĩo das escolas especiais. No entanto, as escolas especiais passaram também a desdobrar práticas sociais discriminatórias $\mathrm{De}$ outro lado, nas escolas comuns caiu uma avalanche de crianças que apresentam condiçóes psíquicas que os docentes não foram preparados para sustentar. Os autores examinam esses dois desdobrimentos e concluem que, seja qual for o caminho a ser adotado, não se deve esquecer que lodal questão escolar, além de dar lugar a uma criança, implica trabathat com um sujeito.

Escolas especiais; educação inclusiva; pais

\section{OPEN LETTER TO PARENTS}

ABOUT SCHOOLS FOR

CHILDREN WITH

DEVELOPMENTAL PROBLEMS

The authors examine the history of special schools. Thirty yeats ago, these schools were empiricists and repetitious, which enhanced perseverations and stereotyped bchaviors. From then on, two different directions were taken: the defense of inclusive school and the transtormation of special schools. However, special schools became also discriminatory and, on the other hand, regular schools received many children with psychic conditions that the teachers could not handle with. The alathors cxamine these two directions and conclude that, whatever is the choosing way, we cannot forget that in school matters we deal not only with a child but also with a subject. Special schools; inclusive education; parents

\section{CARTA ABERTA AOS PAIS ACERCA DA ESCOLARIZAÇÃO DAS CRIANÇAS COM PROBLEMAS DE DESENVOLVIMENTO}

\author{
Alfredo Jerusalinsky \\ Stella Maris $C$. de Páez
}

\section{PREZADOS PAIS:}

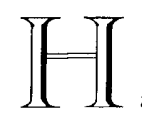

á trinta anos a questão era, por um lado, instalar escolas especiais suficientes - denominadas "diferenciais" naquela época - para dar lugar à

- Psicanalista, diretor dos Centros Lydia Coriat de Porto Alegre e de Buenos Aires, presidente da Fundación para el Estudio de los Problemas de la Infancia de la República Argentina (FEPI), membro da Association Freudiènne Internationale, presidente da Associação Psicanalítica de Porto Alegre.

- 1 Professora de deficientes da voz, do ouvido, e da palavra, mestre em Problemas de Desenvolvimento pela Universidade de Salamanca, Espanha, reitora da Escola de Especialização em Estimulação Precoce de Buenos Aires, ex-diretora de Educação Especial da República Argentina, atual assessora da Direção de Educação Especial da Cidade de Buenos Aires. 
grande quantidade de crianças com problemas de desenvolvimento que não tinham nenhum espaço no sistema educacional. Embora a escola especial já exista há muito tempo - como conceito e como experiência -, a escassez delas, somada a uma perspectiva social e médica francamente pessimista sobre o destino das crianças afetadas por esses problemas, fazia com que a imensa maioria delas ficasse fora de qualquer circulação escolar.

Por outro lado, a prática educativa nas poucas escolas especiais que se ofereciam, geralmente, era orientada de um modo empirista e, portanto, repetitivo, o que as tornava tediosas e pouco criativas. Empenhavam-se em conduzir as crianças pelos caminhos pedagógicos mais duros e pelos conteúdos acadêmicos tradicionais, acreditando que a insistência em si mesma acabaria dando seus frutos, por meio de reeducar funções com exercícios repetidos.

$O$ resultado de tudo isso costumava ser um incentivo às perseveraçōes e um cultivo de estereotipias que terminavam por enrijecer as já dificeis relações sociais do "deficiente". Dificeis, é claro, não por qualquer obstáculo natural, mas pela posição de exclusão em que a sociedade os punha. Constituiu-se assim uma grande massa de crianças, adolescentes e adultos com problemas de desenvolvimento isolados em suas casas, onde a constante passivização cronificava seus sintomas e provocava o acréscimo de graves problemas mentais.

Foi por isso que nós, profissionais e docentes, que víamos esse estado de coisas com olho crítico, investimos esforços em duas direções. Por um lado, para incluir nas escolas comuns as crianças que tinham alcançado condições de participação social (relativizando suas dificuldades cognitivas). E, por outro lado, nos endereçamos tanto a multiplicar as escolas especiais quanto a transformá-las. Para isto, se requeria que nossas intervenções clínicas e educativas alcançassem uma extensão social.

Pode-se dizer, com o passar dos anos, que em uma certa medida o conseguimos. Efetivamente, as escolas especiais se multiplicaram e melhoraram seus métodos, e a atitude social com os "deficientes" tornou-se, visivelmente, menos prejudicial e mais integradora. O pessimismo médico atenuou-se, e com isso as esperanças dos pais cresceram.

Por seu lado, as intervenções clínicas e psicanaliticas mais precoces melhoraram substancialmente as perspectivas psíquicas. $O$ surgimento de conhecimentos mais específicos e recursos técnicos mais afinados a respeito das diferentes formas de deficiencia permitiram preparar melhor os docentes e prover as crianças de auxílios mais específicos e mais pertinentes a sua dificuldade particular. Surgiram, assim, escolas especiais dirigidas ao atendimento de crianças com 
cada diferente dificuldade: escolas para surdos, escolas para deficientes visuais, escolas para crianças com transtornos motores, escolas para deficientes mentais (leia-se intelectuais) e escolas para psicóticos. Nesse conjunto de coisas começaram a surgir vários equívocos: instalaram-se escolas para crianças com síndrome de Down, constituindo uma espécie de gueto entre os "deficientes" mesmos e servindo de pretexto para que as crianças com síndrome de Down não fossem admitidas em nenhuma outra escola. As crianças com deficiências múltiplas não encontravam seu lugar nesse panorama de seleções unívocas e específicas.

Por sua vez, a existência de escolas especiais passou a constituir uma barreira para a aceitação de crianças com problemas de desenvolvimento nas escolas comuns, ainda quando elas tinham condições evidentes de freqüentar o ensino comum e beneficiar-se de uma convivência com pares que representavam o denominador comum do conjunto social. De fato o sistema educativo como um todo, na medida em que passaram a existir lugares educacionais aos quais era possível encaminhar as crianças com dificuldades, se sentiu no direito de rechaçar qualquer forma de inclusão destas. Assim, o simples aspecto externo das crianças e seu rendimento circunstancial instalaram-se como indicadores para seu encaminhamento a uma escola especial.

De fato as escolas especiais começaram a ser povoadas por crianças com problemas de aprendizagem decorrentes de suas condições de privação social e econômica, de suas 
condições familiares e psíquicas, e também por muitas crianças com problemas de desenvolvimento que teriam condições de freqüentar uma escola comum.

Representando inicialmente uma abertura para os deficientes marginalizados, as escolas especiais passaram a desdobrar, parcialmente, uma prática social discriminatória.

O que estava ocorrendo não deveria surpreender-nos. Sempre acontece que quando apontamos nossas baterias significantes para o discurso social para transformá-lo na direção que desejamos, ele responde-nos com o retorno do recalcado. $O$ que quer dizer, neste caso, que os temores do conjunto social de ser confundido com o que escapa daquilo que é reputado como "normal" mobilizam um fechamento narcisista desse conjunto social diante de cada abertura de boas intenções para o próximo marcado por uma diferença.

Certamente, se não podemos evitar esses movimentos reativos, é importante que estejamos advertidos deles. Estar advertido pode significar algumas diferenças no resultado final das coisas.

Esses últimos assinalamentos mostram-se pertinentes, mal começamos a considerar os passos que têm sido dados nestes últimos tempos, na direção de corrigir aqueles equívocos que mencionamos mais acima.

Rapidamente e surpreendentemente muito mais rápido que nunca, em relação ao que costuma ocorrer na resolução de qualquer problema referido aos "deficientes", abriram-se as portas da escola comum para todos os afetados. Tomou-se, para justificar tal ato indiscriminado (vale a ironia do termo), o viés de um direito cerceado a ser reivindicado.

Repetindo o equívoco da Revolução Francesa, declararam-se iguais os que não dispunham de recursos para exercer sua igualdade e legitimou-se a supressão ou restrição dos caminhos para a obtenção ou a ampliação de tais recursos. Efetivamente, na medida em que se tem aberto juridicamente a porta de entrada das crianças com transtornos do desenvolvimento na escola comum - num movimento mundial de indubitável e justíssima reivindicação de um direito humano -, tem-se detido de um modo geral os investimentos destinados a melhorar e aumentar a capacidade das escolas especiais, embora a população de crianças afetadas continue a crescer, e, com toda a evidência, nem todas elas estão em condições de beneficiar-se de modo direto de tal medida. Ao mesmo tempo, são poucas as experiencias em que se desenvolvem os recursos docentes e técnicos, e o apoio específico necessário para adequar as instituições escolares e os procedimentos pedagógico-didáticos às novas condições de inclusão. Com isso, tem despencado sobre a escola comum uma avalanche de crianças que apresentam condições psí- 
quicas, funcionais e de aprendizagem, que os docentes não têm experiência nem condições de sustentar, sem contar, ao mesmo tempo, com o apoio adaptativo necessário. De tal modo que as crianças acabam tendo que suportar a inadequação institucional, num momento de mudanças, e em anos delicados de suas vidas.

Muitos pais lançam-se de modo enérgico e decidido a conquistar um novo lugar para seus filhos nas fileiras da sociedade de todos, na esperança de que a sua participação na comunidade social providencie a recuperação espontânea de funções transtornadas ou posições perdidas.

Tal movimento, na medida em que aponta na direção de acabar com as aparências e o real externo como indicadores do destino de uma criança, gera a expectativa de que haja nisso uma tendência a recuperar a posição do sujeito que ali está em jogo. No entanto, em seguida observamos como retorna com a maior virulência a questão narcísica quando verificamos que muitas crianças são lançadas precipitadamente a esta experiência sem que se tenham preparado as condições necessárias nem nelas, nem nas escolas, para que sua inclusão possa efetivar-se sem transformar-se em um ato de mera aparência. Nessa precipitação, se as aparências saem pela porta, voltam a entrar pela janela.

A questão da inclusão enquanto direito é indiscutivel, e precisamos lembrar que esgrimimos com energia esse direito desde faz já trinta anos, ou seja, muito antes que a legislação formalizasse tal acesso de todos à escola comum. Mas, se ela toma o esti- lo de uma batalha, certamente não podemos esquecer que quem se encontra na linha de frente são nossos filhos e pacientes. É preciso, então, perguntarmo-nos se eles contam com as armas necessárias e suficientes para fazer frente às resistências institucionais que escapam a nosso controle direto, às dificuldades próprias de uma experiência nova e que não conta com recursos e preparação precedente adequada. Porque se eles não contarem com a necessária consistência para enfrentar sem quebras subjetivas a desorientação e vacilações de seus mestres e professores, e atravessar incólumes as tormentas de indignação de seus pais contra as instituições das quais se espera que guiem seus destinos, estão sendo enviados à primeira linha de uma batalha que, se seus pais e advogados ganharem, eles correm todo o perigo de tê-la, antecipadamente, perdido.

Não podemos, nisso, conduzirmo-nos como os mesquinhos generais que, almejando uma vitória política, não medem os custos humanos de sua pretensão. Porque a geração que hoje nos possibilita levantar essa digna reivindicação da inclusão escolar foi, em geral, a que recebeu um apoio específico no seu desenvolvimento. Aquela para a qual, em lugar de recusarmos a diferença, fornecemos as técnicas, recursos e posição subjetiva necessária para que as crianças e jovens com problemas de desenvolvimento lograssem eles mesmos situar-se num pé de igualdade com a sociedade como conjunto. Isso implica pôr o centro de gravidade da problemática da inclusão escolar e social no encontro entre a criança, 
seus colegas e docentes, e não nos escritórios de tramitação jurídico-política. Nestes últimos, procede a fabricação do marco e dos recursos, mas eles não podem recusar tudo o que temos avançado em teoria e técnica da educação e da terapêutica das afecções específicas do desenvolvimento. O trabalho precisa ser complementar e interdisciplinar: as diferenças devem ser reconhecidas para que possam ser atendidas, minimizadas e elaboradas, e, por esse caminho, se possa impedir efetivamente que elas se tornem fonte de discriminação ou exclusão.

E de novo estamos cientes de que quando a criança é capturada como objeto de uma paixão, por mais justa que ela seja, correse nisso o perigo de esquecer aquilo que, se fosse seriamente considerada, poderia mudar verdadeiramente as coisas. A saber: que toda questão escolar, além de dar lugar a uma criança, implica trabalhar com um sujeito. Há um sujeito ali onde há alguém capaz de reconhecer o que de igualdade e diferença o une e o separa do outro. Sem essa posição, a criança fica perdida num mar de olhares e palavras cuja significação jamais poderá compreender.

É aqui que se abre uma série de questões-chave para orientar nossos passos na preparação das condições adequadas para isto que hoje se denomina educação inclusiva.

Afetuosamente,

Alfredo Jerusalinsky Stella Maris C. de Páez 